\title{
PRINCÍPIOS PARA FUNDAR UMA ÉTICA AMBIENTAL
}

\author{
LUIS ALEJANDRO LASSO GUTIÉRREZ \\ Doutorado Interdisciplinar em Ciências Humanas, UFSC
}

\begin{abstract}
At the current environmental crisis many philosophers discuss and reflect on the need to establish an environmental ethic that put limits to the behavior of human beings on the earth, and that, far from the traditional anthropocentric ethics that gives only moral value to humans, gives moral consideration to other beings and thus promotes the biodiversity on earth. Are shown the various proposals for principles that determine the community with moral significance. Keywords: Environmental Ethics, inherent value, moral consideration, moral significance.
\end{abstract}

\section{Resumo}

\begin{abstract}
Ante a atual crise ambiental, muitos pensadores refletem e discutem sobre a necessidade de fundar uma ética ambiental que determine limites ao comportamento do ser humano sobre a terra. Isso para que, longe do antropocentrismo da ética tradicional que dá valor moral somente ao ser humano, possa ser atribuída consideração moral a outros seres e que, desta forma, promova a biodiversidade existente na terra. São colocadas então as diversas propostas de princípios para determinar a comunidade com significância moral. Palavras Chave: Ética Ambiental, Valor inerente, considerabilidade moral. Significância moral.
\end{abstract}

\section{Introdução}

Efetivamente, nas últimas décadas vêm-se incrementando os efeitos da atividade do homem sobre a terra, tais como: destruição de ecossistemas naturais e da vida silvestre, contaminação do ar, do solo, da água, crescente desertificação, mudança climática, entre outros, devido ao modelo de progresso escolhido pela nossa civilização. Entretanto, apesar de tardio, também tem-se incrementado o nível de consciência e de discussão a respeito da dita situação.

Certamente, muitos pensadores provenientes de diversas áreas do conhecimento da cultura, há pelo menos três décadas, e motivados por tal situação, propuseram-se refletir sobre este evidente, mas não tão recente fenômeno global: a degradação ambiental.

Uma faceta dessa reflexão é a referente à Ética Ambiental, que, em termos gerais, tem sido um processo de tomada de consciência crescente através do tempo e que consiste, basicamente, em ir reconhecendo o valor de cada vez mais coisas no mundo que nos rodeia. Em outras palavras, refletindo sobre as relações morais estabelecidas entre os humanos e o mundo natural, a Ética Ambiental propõe os princípios éticos que governam tais relações. De acordo com esta perspectiva geral, a consciência humana começa a estender-se para 
incluir cada vez mais indivíduos ou seres na comunidade dos que têm significância moral.

Assim, um indivíduo com este nível de consciência pode considerar que qualquer ação humana, a princípio, constitui uma ameaça para a natureza, porque deseja que esta seja protegida, ou, de forma ainda mais grave, porque pensa que é moralmente mau ocasionar a morte da natureza. O contexto valorativo não necessariamente inclui princípios morais. Algumas pessoas podem ser amorais, ou do tipo egoístas racionais, como mais adiante veremos. Porém, há pensadores e pessoas que desejam que seus atos e os atos dos outros, incluindo os dos governos e de empresas, atenham-se aos princípios morais. Nessa perspectiva, a solução de qualquer controvérsia sobre a natureza exige apelar a princípios que oferecem orientação moral no trato que dispensamos a ela.

Tal conjunto de princípios que orientem nossa permanência e comportamento sobre a terra e nosso relacionamento com os outros componentes da natureza, constituiria uma ética ambiental no sentido mais geral. Mas, há uma diversidade no entendimento do que significa ética ambiental.

Reconstituiremos a seguir o conteúdo da discussão entre alguns filósofos que se propõem a explicitar o compromisso ético, e na seqüência o analisaremos criticamente.

Diferentes concepções do valor da natureza são consideradas aqui, além da proposta ética tradicional, de caráter antropocêntrico, baseada na racionalidade humana. Assim, contamos com as proposições de Kenneth E. Goodpaster, Aldo Leopold, Tom Regan, Paul Taylor, Lovis G. Lombardi e Peter Singer, entre outros. Todos, a partir de diferentes concepções filosóficas, coincidem em aceitar a tese de que o ser humano e seu entorno são interdependentes, motivo pelo qual uma postura ética é necessária para que não se destrua a terra e com ela os humanos. Tal ética deve refletir a existência de uma consciência ecológica, e a convicção da responsabilidade individual e coletiva pela saúde de todos os seres vivos na terra.

\section{O princípio fundador de uma ética ambiental em debate}

Em termos gerais, distinguem-se as correntes da ética ambiental, entre aquelas com traços antropocêntricos, e as não-antropocêntricas. Como ponto base, temos a escola tradicional da ética, representada por Kant. Esta atribui ao ser humano uma posição especial dentro da natureza, em outras palavras, separa o homem desta e lhe concede maior valor do que ao restante das espécies, colocando a racionalidade como condição necessária e suficiente para atribuir valor moral. O homem tem, desde essa perspectiva, domínio absoluto sobre a natureza, não cabendo qualificar moralmente a relação entre o ser humano e as outras espécies de seres vivos.

Com certo nível de reconhecimento da superioridade humana, surge a escola utilitarista, que aponta a racionalidade humana como critério suficiente, mas não necessário, 
para atribuir valor moral a um ser. Esta escola de pensamento está representada na ética prática contemporânea principalmente por Peter Singer e sua ética da senciência ${ }^{l}$. Por outro lado, mas com características antropocêntricas, pode-se encaixar o conjunto de critérios que procuram o uso racional e responsável do meio natural entendido como recursos naturais.

As propostas éticas não antropocêntricas agrupam a concepção biocêntrica e do valor inerente, representada por Kenneth Goodpaster, Tom Regan e Paul Taylor, de um lado, e, de outro lado, concepções como a de Aldo Leopold com sua ética da terra, que deu origem à ecologia profunda, representada por Baird Callicott, por exemplo. Sobre a base do conceito de paciente moral ${ }^{2}$, os filósofos biocêntricos afastam-se definitivamente da base antropocêntrica da ética clássica, para a qual apenas os agentes morais ${ }^{3}$ têm considerabilidade e relevância morais.

A discussão entre os filósofos começa no sentido da definição das "condições necessárias e suficientes" para se determinar a constituição da comunidade moral. No caminho de ampliação da comunidade com significância moral, os pensadores tentam estabelecer um limite à liberdade humana, quer dizer, dos seres racionais e agentes morais, face aos outros seres existentes na terra. Mas, quais critérios definem quem faz parte, ou não, da dita "comunidade moral"?

O filósofo Kenneth E. Goodpaster, em seu artigo, "On Being Morally Considerable" (1998), retoma a iniciativa de G. J. Warnock, o primeiro a falar de paciente moral, ou seja, daquele que deve ser considerado moralmente, não por ser dotado de razão, linguagem, pensamento e autoconsciência, mas por poder ser prejudicado pelos interesses, decisões e ações dos agentes morais.

Ao estabelecer deveres do agente moral (racional) para com o paciente moral (vulnerável ao dano, dor, sofrimento e morte), Goodpaster e Warnock se afastam da escola tradicional da filosofia moral, segundo a qual, agentes morais têm deveres apenas em relação a outros sujeitos racionais, seus iguais.

Goodpaster se propõe a construir uma discussão de ordem normativa e factual para definir o dever do agente moral (ser racional dotado de liberdade, razão e linguagem), para com o paciente moral (ser que pode ser afetado pelas ações dos agentes morais). Esta discussão é construída através de uma argumentação baseada nas seguintes distinções: entre considerabilidade moral e direitos morais; entre considerabilidade moral e critérios de significância moral; entre questões de inteligibilidade e de substância normativa; e, entre questões de ordem operativa e questões de ordem regulativa. Considero importante levantar tais distinções para esclarecer conceitos que fazem parte da discussão e propostas de outros filósofos.

A primeira distinção é entre considerabilidade moral e direitos morais. A considerabilidade moral, uma categoria mais ampla, expressa a necessidade de esclarecer os critérios e argumentos que sustentam ou fundamentam a definição dos seres que merecem consideração (atendimento, reconhecimento) na comunidade moral. Ser moralmente considerável ainda não implica em "ter" direitos morais, afirma Goodpaster. Para ter direitos morais, por sua vez, o sujeito precisa ser 
capaz de assumir responsabilidades e deveres em relação àqueles que têm considerabilidade moral nessa comunidade, pois o direito está vinculado à idéia de justiça, autonomia e reciprocidade.

A segunda anotação, feita por Goodpaster para aclarar o uso do conceito de considerabilidade moral e dar lugar àqueles que não têm direitos morais mas devem ser respeitados, é a da distinção entre considerabilidade moral e significância ou relevância moral. A primeira responde a duas ordens: por um lado, à ordem regulativa, quando relacionada a um principio estratégico para formular regras gerais de ação; e, por outro lado, à ordem operativa, entendida como a que define as regras de ação. O critério da significância ou relevância moral, por sua vez, está destinado a governar juízos comparativos de peso moral, em caso de conflito. Quando, no caso de conflito, todos os seres e coisas vivas envolvidas têm considerabilidade moral, há que se dispor de outra regra para dirimi-lo. A decisão precisará ser tomada com base, então, na regra da relevância da vida para aquele que a vive.

A terceira distinção está colocada entre o que são questões de inteligibilidade e substância normativa, associadas às seguintes perguntas, respectivamente: Qual tipo de ser pode ser chamado a merecer consideração moral? E, qual tipo de ser, como matéria ética de fato, merece consideração moral? Enquanto a primeira pergunta exige uma resposta descritiva, enunciando condições objetivas reconhecidas como critério digno de consideração moral, a segunda entra definitivamente no âmbito da reflexão moral, exigindo uma resposta que não pode ser elaborada a partir dos dados fornecidos pela ciência ou por qualquer outro tipo de investigação. Essa resposta deve estar fundamentada em um princípio moral.

A quarta distinção está associada às nossas limitações cognitivas como seres humanos, para definir quais demandas morais são relativas a esses limites e quais não, sendo agrupadas no nível operativo e no nível regulativo. Embora no nível regulativo nossa razão nos permita alcançar um princípio moral que pode ser considerado válido por qualquer agente racional, a aplicação desse princípio, no nível operativo, pode encontrar limites.

Goodpaster propõe estabelecer um critério para limitar a liberdade humana e conclui que estar vivo é a condição necessária e suficiente para entrar na comunidade moral. "Vida", então, é o critério que responde duas questões básicas da ética prática contemporânea: 1. Qual é o critério para definir os afetados pelas ações dos agentes morais? 2. Qual é o critério para definir os sujeitos afetados?

Assim, Goodpaster rejeita o princípio egoísta da filosofia moral moderna, que coloca a razão como critério único para determinar a comunidade moral. $O$ autor aponta, adicionalmente, como suficiente mas desnecessário, o critério da senciência, estabelecido por correntes filosóficas de corte utilitarista, para finalmente concluir que a vida (racional, senciente, não-racional e não-senciente) deve ser o critério para definir quem faz parte da comunidade moral.

Voltando à corrente antropocêntrica, importa citar a G. J. Warnock, que a partir de discussões sobre a racionalidade de crianças e pessoas em estado de coma ou com retardos 
e doenças mentais, propõe que o critério de considerabilidade moral seja estabelecidos com base na capacidade de sofrer. Peter Singer, em sua obra, Practical Ethics (1979), influenciado por essa proposta, sugere a liberdade de mover-se para auto prover-se, e a capacidade de sentir consciente ou senciência (sofrer e fruir) como critério de considerabilidade moral. Frankena (apud Goodpaster, 1998), por seu lado, considera que seres não sencientes simplesmente não proporcionam razões morais diretas para merecerem respeito, a menos que sejam potencialmente sencientes.

Warnock, Frankena e Singer adotam o critério da senciência como suficiente para definir os seres dignos de consideraçãona comunidade moral, mas Goodpaster considera que este critério (eas razões expostas por tais autores), embora suficiente, não é necessário. Ele considera que há um critério mais forte, mais explícito, não restritivo e não arbitrário para definir o conjunto da comunidade moral: estar vivo.

Em seu artigo crítico à ética de Goodpaster, "Are Mere Things Morally Considerable?” (1980), W. Murray Hunt propõe a substituição do critério vida pelo critério existência (estar em existência ou ter existido). Em sua réplica, "On Stopping at Everything: A Reply to W. M. Hunt" (1980), Goodpaster inicialmente resgata a afirmação de Feinberg, de que um ser sem interesses é um ser incapaz de ser afetado ou beneficiado. Para Goodpaster, considerar o interesse de seres inanimados é simplesmente incoerente. Assim, se há interesse em preservar as características de uma coisa, esse interesse não é da coisa, mas sim de quem a possui.

Goodpaster avalia os conceitos de beneficência e não-maleficência como centrais na discussão. Segundo ele, o conceito de interesse parece ter sido esquecido na argumentação de Hunt. Goodpaster reitera que um ser não precisa de um sistema nervoso central ou sentimentos para ter interesse, daí a senciência ser desnecessária, estar vivo é suficiente. Mas, manter-se vivo é o interesse primordial de cada ser vivo, e é esta a característica que todo sujeito moral deve se preocupar em respeitar. Goodpaster aponta a necessidade de trazer o conceito de consideração moral no sentido relevante, para evitar confundi-la com outras formas de consideração, que não são formas de beneficência e ou não-maleficência. Esclarece, por outro lado, que o fim da vida acaba também com o dever ético do sujeito moral agente em relação ao ser antes vivo.

Numa outra perspectiva, em seu artigo, "The Nature and Possibility of an Environmental Ethics" (1981), Tom Regan propõe o conceito de valor inerente à vida de cada ser. Este conceito pode ser entendido como o bem próprio (estar bem na vida) no modo específico da vida de cada ser. Em outras palavras, há seres naturais não-conscientes que podem ter valor a seu próprio modo (especifico) independentemente de interesses e valorações utilitaristas humanos (valor instrumental).

Por outro lado, Joel Feinberg introduz o conceito de interesse, baseado no princípio que afirma que para manter status moral, alguém ou algo, deve ter interesse, deve ser capaz de beneficiar-se ou resultar afetado negativamente pela ação de um agente moral. Assim, ter status moral é ter direitos, é ter argumentos para enfrentar os interesses de outros que agem de determinada forma, ou deixam de agir. $\mathrm{Na}$ perspectiva de Feinberg, a consciência, num 
ser vivo dotado de sensibilidade, é condição necessária e suficiente para possuir interesse.

Evidentemente há convergências e divergências na definição filosófica da comunidade com significância moral. Vale a pena levantar algumas delas.

Tom Regan critica a adoção do critério da senciência, por Peter Singer, pelo vínculo que encontra com o interesse no marco de uma ética utilitarista, alvo de sua crítica. Na essência do conceito de valor inerente, proposto por Regan, há interesses que devem ser respeitados, embora não possam ser representados por experiências de dor e de prazer. Neste sentido, para Regan, a senciência é, então, um critério que pode ser suficiente, mas não necessário para promover a proteção dos interesses de pacientes morais, quando esses são destituídos de sensibilidade, no sentido psicológico que costumamos empregar.

Nessa perspectiva, Tom Regan propõe o conceito de vulnerabilidade, entendendo que um ser, por exemplo, aquele destituído de razão ou com um nível de consciência menos aguçado que o humano, pode sofrer conseqüências danosas em decorrência da ação de um agente moral ou sujeito racional. De acordo com este critério, inclui-se o interesse de seres não-racionais e também não-sencientes no âmbito da comunidade moral.

Por outro lado, Regan introduz o conceito de sujeito-de-uma-vida, com o que define melhor os seres com relevância ou significância moral. São estes, todos aqueles capazes de diferenciar, por sua própria experiência, aquilo que lhes faz bem, ou mal, de acordo com seu tipo de vida.

No caminho para definir uma ética não antropocêntrica, uma ética "genuinamente ambiental", conforme a concebe Regan, todos os seres conscientes e alguns não conscientes devem ter estatuto moral. Para isso, duas condições são apresentadas como necessárias: primeiro, que uma ética ambiental defenda a existência de seres sencientes não-humanos com significância moral; segundo, que a classe de seres com significância moral seja ampliada, para abranger a classe de seres não-conscientes.

Contudo, é na essência do conceito de valor inerente que Tom Regan e Paul Taylor fundam sua crítica às escolas tradicional (fundadas sobre o argumento do valor instrumental da vida animal e vegetal) e utilitarista da ética, fundada sobre o argumento do valor intrínseco da vida senciente, calculado pela somatória do prazer e da dor, conforme o propõe Peter Singer. Regan e Taylor reconhecem que o valor inerente é um só, e que não tem gradação, quer dizer, por ser um valor moral, é igual para todos os seres que o possuem.

Há, pelo menos, cinco idéias relacionadas ao conceito de valor inerente, conforme o aponta Regan:

1. A presença de valor inerente num objeto natural, independente de qualquer consciência, interesse ou apreço de qualquer ser consciente por ele;

2. A presença de valor inerente num objeto natural resulta do fato de possuir outras características; 
3. O valor inerente de um objeto natural é propriedade objetiva dele;

4. O valor inerente é de tal ordem que, diante dele, a única atitude apropriada é a de respeito;

5. A admiração respeitosa do que naturalmente tem valor inerente leva à adoção do princípio de preservação ambiental.

O filósofo Lovis G. Lombardi, em seu artigo, "Inherent Worth, Respect and Rights"(1983), baseado no conceito inicialmente levantado por Regan, e também defendido por Paul Taylor em, “The Ethics of Respect for Nature”(1998), faz uma crítica à defesa do valor inerente igual da vida, argumentando que, diferentes seres vivos podem ter níveis ou graus diferentes de valor inerente. No seu entender, dependendo do grau de valor de uma vida, deve-se respeitá-la, mas sem atribuir qualquer direito a ela. Isso quer dizer, a vida com menor grau de valor poderia ser eliminada, caso sua continuação representasse ameaça a outras vidas com maior grau de valor. Para essas últimas, existiria o direito de viver, não para aquelas.

Em termos gerais, Lombardi propõe uma posição intermediária entre Kant e Paul Taylor, apontando inicialmente que o fato da singularidade de cada vida individual, referido por Taylor, não basta para explicar a tese do valor inerente igual da vida de animais e plantas.

Para fundamentar sua crítica, Lombardi baseia-se nas qualidades expressas (que dependem do observador) e nas capacidades (alguma função) dos seres vivos em apreço. Com vários exemplos, Lombardi chega ao ponto de considerar necessário, na perspectiva de sua argumentação, aceitar a superioridade humana - o ser humano sempre saberá ver a utilidade dos objetos naturais. Esta conclusão se baseia numa quantidade de capacidades ou habilidades que o ser vivo possui, reconhecidas, no entanto, pela consciência humana.

Paul Taylor (1998) responde à proposta de Lombardi, de graduar níveis de valor inerente para diferentes tipos de vida, questionando em seu artigo: "Are Humans Superior to Animals and Plants?" (“São os humanos superiores a animais e plantas?". Taylor se baseia no conceito de bem próprio, segundo o qual, cada ser vivente busca seu próprio bem à sua maneira exclusiva. Uma vez que entendemos isso, olhamos para os demais seres viventes como olhamos para nós mesmos. Por conseguinte, estamos preparados para dar o mesmo valor à sua existência, dado à nossa, ainda que sejam distintas e incomensuráveis. Através de vários exemplos e do conceito de bem próprio, Taylor conclui que o valor inerente de um ser vivo não poder ser graduado. A igualdade do valor da vida de humanos e de não-humanos não exclui a possibilidade da justiça entre eles. Assim, temos uma razão para não fazer aos não-humanos o que não aprovamos que seja feito conosco. Isso requer abrir mão de preconceitos antropocêntricos que nos colocam numa posição hierárquica, de domínio tirânico sobre o bem próprio de plantas e animais. 


\section{Considerações Finais}

Vida, senciência, existência, são, entre outros, critérios que fazem parte da rica discussão desenvolvida por essa série de pensadores que buscam princípios fundadores de uma ética ambiental, capaz de pôr limites à expansão do domínio do ser humano sobre a vida na terra.

Foi visto como, para além do antropocentrismo da ética tradicional, fundada no critério da racionalidade para dar valor moral a um ser, estão os que propõem que uma vida se define pelo que representa de bem em si mesma, para aquele que a vive, sem que seja necessário fazer uma referência à utilidade dessa vida para benefício alheio. Nesse sentido, deve ser formulada uma ética que respeite todo tipo de vida e não só uma ética baseada nas necessidades de produção e reprodução humanas, ou em parâmetros tais quais o da sensibilidade onde o prazer e a dor desempenham um papel importante.

Foram referenciados também os que defendem que a teoria do valor, pelo fato de ser antropocêntrica, age em favor do valor intrínseco dos seres humanos, considerando todas as outras coisas, vivas e não-vivas, como valiosas só instrumentalmente, ou seja, como valiosas somente na medida em que sejam meios ou instrumentos que possam servir aos propósitos e interesses de seres humanos.

Ainda, há os que vêem na postura não antropocêntrica a possibilidade de mudar suas condições em favor de outro tipo de aproximação que inclua o iniludível papel de modificar nossos valores e nossa conduta, informando sobre nossa responsabilidade como seres vivos e como parte do ecossistema, para respeitar as condições de nossa vida e das outra formas de vida, ou seja, uma mudança de concepção na direção de uma igualdade biocêntrica (Paul Taylor, por exemplo).

Evidencia-se, em todos estes pensadores, a necessidade de incorporar princípios éticos que fundam valores orientadores de um melhor comportamento do homem sobre a terra, e que pouco a pouco, consigam apaziguar a tendência antropocêntrica, que, claramente gerou a degradação e risco ao qual estão expostos hoje todos os tipos de vida e existência de seres sobre a terra. Um primeiro passo é fomentar uma atitude parcimoniosa, garantindo que os humanos não queiram cada vez mais do que não existe em abundância, o que evidentemente expressou a diminuição significativa das possibilidades de vida a outros seres. 


\section{Notas}

${ }^{1}$ Senciência: capacidade de sentir consciente (sofrer e fruir).

${ }^{2}$ Paciente moral: todo ser que pode ser afetado pelas ações dos agentes morais, podendo fruir benefícios ou sofrer malefícios.

${ }^{3}$ Agente moral: ser racional possuidor de capacidades que lhe permitem agir moral ou imoralmente, (liberdade, razão e linguagem). Cf. TAYLOR, Paul W. Respect for Nature, p. 15-17. 


\section{Referências bibliográficas}

FELIPE, S. T. Da considerabilidade moral dos seres vivos: a bioética ambiental de Kenneth Goodpaster. In.: ethic@, Florianópolis v. 5, n. 3, Julho de 2006, p. 147-151.

GOODPASTER, K. E. On Being Morally Considerable. In.: ZIMMERMAN, Michael E. et alii. Environmental Philosophy. From Animal Rights to Radical Ecology. New Jersey: Prentice Hall, 1998, p. 56-70.

. On Stopping at Everything: A reply to W. M. Hunt. In.: Environmental Ethics. University of North Texas, Fall 1980, v. 2, n. 3, p 281-284.

HUNT, W. M. Are Mere Things Morally Considerable? In.: Environmental Ethics. University of North Texas, Spring 1980, v. 2, n. 1, p 59-65.

LOMBARDI, L. G. Inherent Worth, Respect and Rights. In.: Environmental Ethics. University of North Texas, Fall 1983, v. 5, n. 3, p 257-270.

REGAN, T. The Nature and Possibility of an Environmental Ethic, In.: Environmental Ethics. University of North Texas, Spring 1981, v. 3, n. 1, p 19-34.

SINGER, P. Practical Ethics. 2nd. Cambridge University Press, 1993.

TAYLOR, P. W. The Ethics of Respect for Nature. In.: ZIMMERMAN, Michael E. et alii. Environmental Philosophy. From Animal Rights to Radical Ecology. New Jersey. Prentice Hall, 1998, p. $71-86$ 